\title{
Evaluation of fish sperm quality
}

\author{
C. Fauvel ${ }^{1, *}$, M. Suquet ${ }^{2}$, J. Cosson ${ }^{3}$
}

\footnotetext{
${ }^{1}$ Ifremer, Station Expérimentale d'Aquaculture, Palavas les Flots, France

2 Ifremer, Station Expérimentale d'Argenton, Argenton, France

${ }^{3}$ CNRS, UMR 7009, Univ. Paris VI, Station Marine, Villefranche sur mer, France

*: Corresponding author : Christian Fauvel, email address : cfauvel@ifremer.fr
}

\begin{abstract}
:
The development of cheaper technical tools and the availability of well established assay kits provide today the spermatologists with several devices for objective and quantifying assessment of sperm quality. The present paper reviews modern methods on sperm concentration assessment, morphometry, motility processes through flagellum studies, motility objective assessment by computer assisted sperm analysis (CASA), sperm integrity and energetic state measurements.
\end{abstract}




\section{Introduction}

The recruitment of wild fish as well as the controlled production in aquaculture are biological events strongly linked to the reproductive success and in particular, with the fertilization of mature oocytes. Thereafter, additional life cycle phases contributing to recruitment are influenced by successful larval development (particularly the sensitive stages at first food intake). As a general feature, after seasonal gametogenesis, fish generally breed seasonally. During mating, gametes are released into the water where they are fertilized. Both intrinsic gamete quality and quantity, and environment of gamete fusion determine fertilization success. As a consequence, fertilization is an integrative response to multiple factors which may hide variations of sperm intrinsic quality. For instance, whereas no sperm quality effect on fertilization was detected in factorial crosses in trout (Nagler, 2000) and seabass (Saillant et al., 2001) where egg quality effect was significant. In contrast, Kaspar et al. (2008) showed significant differences of fertilization in carp due to sperm in crosses using either individual males or mixtures of different sperm (hetero-sperm) where variation in fertilization was only explained by strong differences of sperm swimming velocity. The latest reviews (Bobe \& Labbé, 2009; Alavi et al., 2008; Cabrita et al., 2009) clearly demonstrate that most of the characteristics of sperm contribute to the overall quality but that none of these is sufficiently integrative to describe fully the ability of sperm to fertilize ova. Moreover, the study of sperm quality can greatly profit from a standardization of analytical methods and tools. After a short review of sperm quality determination, the present paper attempts to propose "easy-to-share" methods for the assessment of major sperm parameter such as concentration, motility, morphometry, energy content, membrane 
integrity and DNA state. These parameters will be addressed without entering into details on specialized biochemical or molecular component analysis which may affect fertility in line with these major sperm characteristics.

\section{Sperm quality determinism}

The factors affecting sperm quality have been extensively described in the recent reviews cited above. The following table (table 1) attempts to summarize the different factors largely reported in the literature to influence sperm quality in relation to sperm characteristics evoked in the current paper. It is noteworthy that, although poorly documented, genetic selection may alter sperm quality and fertility and may become an actual concern. Zohar (1996) reported that selection of interesting commercial strains of salmon resulted in a reduction by 20 times the sperm volume produced by males and Agnèse et al. (2005) reported a decrease of fertility at the fourth generation of domestication in Heterobranchus longifilis. More recently, it seems that there is an increasing use of $\mathrm{GnRHa}$ in salmonid hatcheries to prevent the decrease of sperm production in selected broodstocks (Haffray, personal communication) although it is not confirmed by publications.

\section{Sperm concentration}

The concentration of spermatozoa in the semen is easily assessed by different techniques such as microscopy counting, spectrophotometry, flow cytometry and determination of spermatocrit values (see review in Alavi, et al., 2008). However the different methods proposed present some inconveniences. Counting (which is the basic method) allows assessing sperm number with an acceptable variability due to dilution and counting 
errors and evaluated to $6 \%$ for 300 spermatozoa per observation when counting of 1/500 diluted sperm was repeated 3 times ((Suquet et al., 1992). It is the cheapest way to assess concentration of sperm but the main concern of this method is that it is time consuming and this way, not compatible with the further use of sperm such as conditioning for preservation or aliquoting for multiple crosses in genetic studies.

The requirement of a fast assessment of spermatozoa concentration can be fulfilled by different techniques such as photometry, cytometry including Coulter counter and centrifugation.

Photometric evaluation was reported for different species using different wavelengths of visible lights for which the apparent absorption of the light is mostly due to the turbidity of the medium (Billard, 1986; Suquet et al., 1992; Cieresko and Dabrowski, 1993). The scanning of seabass sperm absorption along the light spectrum revealed a constant increase from 500 to $300 \mathrm{~nm}$ then a stronger increase occurred with a peak at $260 \mathrm{~nm}$ and at last the absorption rises up to its maximum at $210 \mathrm{~nm}$. The best correlations between sperm counts and sperm optical densities were observed for $260 \mathrm{~nm}$ (Fauvel et al., 1999). Since this first result, the sperm of different species have been scanned and showed very similar spectra (Fig 1) and the regressions between optical density and sperm concentration were specific (Fig 2, Table2). On a practical point of view, for fish sperm, the right semen dilution for the analysis is between 1/250 and 1/500 (sperm / distilled water) in all the fish species studied. Since nucleic acids absorb mainly at 260 $\mathrm{nm}$, the optical density of semen observed at this wavelength probably reveals mainly the DNA content of the medium almost exclusively originating from the spermatozoa. The differences of absorption slopes observed between species may be due to specific DNA genomic content which is adapted to the different species. 
Although spermatocrit has been used for sperm concentration assessment (reviewed in Alavi et al., 2008), the method is not easy to apply to marine fish. Since spermatozoa do not sediment efficiently even under long centrifugation runs at high rotational velocities, the spermatocrit remains very high (between 80 and 100\%) or erratic. Spermatozoa and seminal liquid may have a similar density preventing separation by centrifugation. Furthermore, centrifugations applied to sperm for electronic microscopy preparation often result into strong damage of spermatozoa morphology hence modifying cell volume and consequently the ratio between seminal fluid and packed cell volumes. For example, turbot (Psetta maxima) sperm must be centrifuged at speed lower than 1000 rpm in order to avoid cell damages.

More recently, flow cytometers or Coulter counters have been used to assess precisely the sperm concentrations in milt samples but these types of devices are expensive and not commonly available in average size laboratories. Their maintenance costs are high and thus are useful only in large institutions where many samples of different particles types have to be handled daily. However these expensive methods can provide complementary indications such as cell volume (Coulter counter) or physiological state of sperm (flow cytometer, such as Nucleocounter SP-100; see below).

At last, recent progresses in digital camera image recognition and the availability of a full suite of simple image analysis software packages allow quick counting of sperm, providing options for compromises between efficiency, time and costs. For example, in tuna sperm research, aliquots of sperm at the right dilution in distilled water were allowed to settle for 5 minutes on the hemocytometer, thereafter they were photographed after adequate focusing of the microscope. Photographs were immediately recorded on a simple laptop and analyzed using image $\mathbf{J}$ free software after binarisation: the number of 
sperm thus counted was perfectly correlated with control counting obtained by 2 independent observers using microscopy counting (Mylonas et al., 2007).

As a conclusion for this parameter, sperm concentration can be assessed precisely and quickly by means of sophisticated and costly tools which can provide other sperm characteristics about viability (see below) but new cheap applications such as small mobile single wavelength (even in UV) photometers or image analysis can successfully be used with an acceptable time lag for further use of sperm.

\section{Sperm morphology}

Spermatozoa are isolated cells subject to variable environments from the testis to the fertilizing medium. Moreover they can be damaged by xenobiotics, altered by genetic mutation or ageing and at last they can be partially degraded by conservation protocols. Under these different causes, modifications of sperm structure such as flagellum length or sperm head size have been observed in mammals. The recent techniques of image analysis were adapted in the 90's to describe mammal sperm morphology through the development of ASMA (Automated Sperm Morphology Analysis). This method was first applied to fish sperm by Van Look and Kime (2003) studying the effect of increasing dose of mercury on sperm quality. Later on, ASMA was used to assess the effects of HCG on spermiation in European eel (Asturiano et al., 2006), the effects of dilution media for cryopreservation (Peñaranda et al., 2008) and the possible correlation between sperm morphology and swimming performance. (Tuset et al., 2008).

The observation of similar sperm head size by ASMA and scanning electron microscopy validated the use of ASMA for a quick assessment of spermatozoa morphology (MarcoJimenez et al., 2008) but it must be emphasized that both techniques need a chemical 
fixation of the cells which may easily provoke artifacts.

Developed for $50 \mu \mathrm{m}$ long mammal spermatozoa, ASMA may become an interesting tool for batch analysis of fish spermatozoa which are ten time smaller. However attention must be paid to the possible distortions of fish sperm morphology due to the necessary fixation protocols

\section{Sperm motility}

\section{Subjective assessment}

Sperm motility evaluation technologies have been regularly and exhaustively reviewed in the past five years (Rurangwa et al., 2004; Cosson et al., 2008 a, b; Cabrita et al., 2009, Bobe and Labbé 2009). The simple observation of sperm under a microscope at a magnification between $\times 10$ and $\times 25$ using a glass slide with or without coverslip, has been so far extensively used in order to qualify spermatozoa properties before their use in fertilization trials. This type of observation provides a coarse evaluation of sperm quality by motility criteria since it allows only assessing classes in terms of percent of motile sperm and motility duration defined by the time period leading to cessation of any progressive movement.

Although inaccurate and subjective, such a method highlighted the difficulties to objectively analyze the motility of spermatozoa and allowed defining the bases for further individual analysis. A reliable motility assessment actually requires i), a two step dilution with a predilution in a non activating medium and ii) a high final dilution rate $(>1 / 1000)$ in the activating medium adapted to either final sperm concentration and motility efficiency in order to avoid heterogenous triggering of motility (Billard \& 
Cosson, 1992). The use of misfit activation conditions in the past may have driven to erroneous data. However, if this type of assessment provides the general features of fish sperm motility by a batch observation, it does not allow quantifying movements objectively and prevents establishing correlations between sperm movements and fertility and also correlations between factors determining sperm quality and sperm movement.

\section{Description of motility process}

The motility of fish sperm has been objectively described by different ways according to the aim of the studies. The use of phase contrast or dark field microscopy improved considerably the possibilities to observe both the head and the flagellum of the spermatozoa. The application of different types of high speed video recording or the application of stroboscopic light sources provided high quality static pictures of a same flagellum in different successive positions. This also allowed describing the frequency of flagellar beating, the shape, amplitude and number of flagellar waves and their variations and propagation responsible for the progression of the spermatozoa. Such techniques describing very accurately the initiation and the future variations of flagellar beats showed that waves initiate at the junction between head and flagellum and progress towards the tip of the flagellum while, on the contrary, the decrease of motility efficiency observed for fish spermatozoa during their motility period is mostly due to a dampening from the distal part of the flagellum, which seems to be a general feature for fish species studied so far (see review in Cosson et al., 2008a, b and Cosson, 2010).

\section{Quantification of sperm motility.}


Although eye assessment of velocity was still recently used (Gage et al., 2002; 2004), several works in the past decade have reported the use of different Computer Assisted Sperm Analysis (CASA) systems to assess sperm motility in fish. The CASA softwares integrate the successive positions of the heads of moving spermatozoa in consecutive frames of video records to calculate the trajectories and their characteristics. CASA describe different parameters of sperm swimming linked to velocity e.g. Curvilinear Velocity (VCL) or instant speed (frame to frame displacement) along the real track, Average Path Velocity (VAP)or velocity along a smoothed track, Straight Line Velocity (VSL) or progressive velocity following the straight line from the origin to the end of the track during the corresponding period of time and other parameters linked to the wobble of sperm head such as Mean Angular Displacement (MAD), amplitude of Lateral Head Displacement (ALH) and Beat Cross Frequency (BCF) and linearity. At last, the ratio between average path and straight line path is used to describe the straightness of the trajectories (reviewed in Rurangwa et al., 2004).

Attention should be paid that data produced by CASA are partly calculated from other data also produced by CASA. For example wobble is the ratio between VCL and VAP. The choice of the velocity parameter describing the motility also depends on the video camera used. According to Wilson-Leedy and Ingermann (2007), low speed recording will hide the modifications of tracks during large time intervals $(1 / 25 \mathrm{~s}$ for example) so that VCL and VAP would be quite similar. In that case, VAP would be a more stable index of velocity. CASA assesses objectively at the same time swimming parameters of a much larger number of spermatozoa than can do observers and it provides individual characteristics as well as general features of the population. As such, the CASA carrying out a larger sampling would provide a better evaluation of semen quality. Furthermore, 
CASA appears to be especially well adapted for fish spermatozoa, the motility of which lasts for very short and varies very quickly; even though fish sperm starts swimming with high velocity, the rapidity of CASA analysis authorizes studying the shape of motility decrease in terms of both percentages of motile cells and movement quality (velocity, straightness and so). Oppositely, when considering a restricted time period inside their motility phase, fish sperm moving behavior presents much less heterogeneity than mammalian spermatozoa (Cosson, 2010).

However, the large data sets generated by CASA are generally reduced to the mean values of the different parameters which were sufficient to reveal significant differences in experimental protocols (Rurangwa et al., 2001; Linhart et al., 2005) although these mean values hide the large individual variability of motility as shown for tuna sperm for example (Fig 3 ). A recent approach by principal component analysis followed by a clustering of spermatozoa motility types showed the variability of motility is mostly explained by the velocity (55\% of total variance) and the wandering (erratic movement) (25\% of total variance) and allowed segregating 4 major types of spermatozoa the proportion of which varies according to different factors such as male, activating medium, time after activation (Martinez Pastor et al., 2008). Such an approach appears very interesting since it may propose more discriminating evaluation of quality factor effects by focusing the study to the more reactive clusters of spermatozoa. Currently, a dozen of CASA systems are commercially available but they lead to some concerns. They are quite expensive, generally conceived and adapted for long motility mammal sperm analysis. However they can be used for fish sperm if they can generate the swimming parameters over a very short period of time in order to allow studies of rapid motility decrease of fish gametes. They are more or less easy to use and it is quite 
difficult to know how the software proceeds to generate the data so that the results, coming out of a sort of "black box", may be linked to the type of analyzer used and may not be easily compared to results obtained from other softwares.

The CASA system recently developed by Wilson-Leedy and Ingermann (2007) in the environment of image $\mathbf{J}$ software freely available from NIH internet site (Wilson-Leedy and Ingermann, 2006) has been tested in different species and recently in zebrafish (Wilson-Leedy et al., 2009)

It has been possible to evaluate the motility and the velocity of seabass sperm as well as of tuna using a microscope (Axiolab, Zeiss) with planar objective equipped with a CCD camera (Sony SSC-DC50AP) recording 25 video frames/s linked to a simple notebook (Samsung NC10) where sequences have been recorded as AVI movies (fig 4 ). The image $\mathbf{J}$ software written in JAVA language can be improved through new plugins created by users or according to specific their demands. Image $\mathbf{J}$ provides two main advantages: the soft is freely available on Internet and its calibration is easy. So it may be a good opportunity to have an easy access to sperm motility parameters with very simple and affordable equipment and to facilitate interspecific comparisons of sperm motility using standardized parameters, especially when obtained in different laboratories.

Motility can quantify sperm intrinsic quality sooner and more objectively than biological integrative assays such as fertilization rate but other characteristics of spermatozoa can be subject to standardized analyses in order to better approach sperm quality.

\section{Membrane integrity}


At a subcellular level, sperm quality can be assessed by the integrity of the plasmic membrane of the spermatozoa. Plasmic membrane controls ion and water exchanges between intra and extracellular medium which trigger the bendings of the axoneme by mechanisms recently reviewed by Cosson et al. (2008a) and Inaba (2008). On a practical point of view, the integrity of membrane has been studied by evaluation of the differential penetration ability of dyes such as eosin/nigrosin or eosin alone and simple observation under microscope in cases of mammals (Bjorndahl et al., 2004) and fish (Zilli et al,. 2004). More recently, the quality of semen has been assessed by the use of fluorescent DNA markers such as Hoechst 33258, Propidium iodide (PI) or better, by the use of kits containing specific markers (Sybr-14/PI) allowing a simultaneous observation of both live and dead sperm. The percentage of viability was assessed by direct counting or image analysis under microscope (Asturiano et al., 2007; Flajshans et al.,2004), by flow cytometry (Ogier de Baulny,1997; Cabrita et al., 2005a) and lately by means of an automatic counter (Nucleocounter SP-100,Chemometec, Denmark) which records by means of a CCD camera, successive pictures of spermatozoa subjected to PI, and provides viability and sperm concentration based on image analysis of about 1500 spermatozoa within one minute with an excellent repeatability (Nynca \& Ciereszko, 2009). This counter is portable and very convenient for field operations. However it is too expensive for only sperm concentration studies but the system becomes very interesting if used for both concentration and viability assessment currently based on fluorescent DNA marker penetration and, in the future, applied to mitochondrial efficiency assessment through dyes such as Rhodamine 123 (Ogier de Baulny, 1997) or JC1 (5,5',6,6'-tetrachloro-1,1',3,3' tetraethylbenzimidazolylcarbocyanine iodide) (Asturiano et al., 2006). 
Among the causes of infertility, damage to the DNA of spermatozoa has been pointed out particularly in relation to cryopreservation conditions. The various recent reviews mostly agree to consider that the analysis of DNA by alkaline single cell gel electrophoresis known as "Comet assay" is a reliable, sensitive and cheap method to detect DNA strand breaks. Different DNA markers such as DAPI (Zilli et al., 2003) or Ethidium bromide (Labbé et al., 2001, Cabrita et al., 2005b) can be used to reveal the spots. Only reported to assess deleterious effect of cryopreservation in fish sperm, the method also reveals variations of percentage of damaged spermatozoa in consecutive ejaculates of a same male in trout and differences between males concomitantly stripped (Labbé et al., 2001). Other methods of DNA integrity studies such as "TUNEL" and "SCSA" were reviewed by (Cabrita et al., 2009) but have not been extensively used in fish sperm studies so far. The causes of the occurrence of significant percentages of damaged spermatozoa in control males (from 10 to $38 \%$ according to studies and species) and the consequences on fertility would be worth studying.

Membrane integrity can also be evaluated indirectly by microscopic observation at high magnification of the morphology of sperm cells, either on sperm dispersed in a non swimming medium for prevention of movement during observation or using stroboscopic illumination for sperm in movement. Such dynamic morphometry coupled with image analysis brings precious informations regarding head-tail junction integrity or on the presence of blebs along the flagellum, or even loops appearing at the tip of flagella (Perchec et al., 1996), the later providing indications that osmotic trauma were imposed to sperm cells. 


\section{Energy content}

Sperm motility is sustained by ATP hydrolysis, catalysed by dynein ATPase which drives the sliding of adjacent doublets of microtubules in the flagellum, leading to the generation of flagellar beating (Gibbons, 1968). First described by Christen et al. (1987) in trout, ATP hydrolysis was reported during the movement phase of some fish species such as carp (Cyprinus carpio), turbot (Psetta maxima), (Perchec et al., 1995; Dreanno et al., 1999), chondrostean (sturgeon) (Billard et al., 1999) or sea bass (Dreanno et al., $1999 \& 2000)$.

Fish sperm ATP content was evaluated by HPLC (Moal, 1989) or by bioluminescence ( Perchec et al., 1995) and by NMR (Dreanno et al., 1999). The luminescence technique using now microplate luminometers is easy and rapid since it can be processed through reliable commercial assay kits and results can be generated within two to three hours. This technique was recently used to study the catabolism of intracellular ATP during the movement of Eurasian perch (Perca fluviatilis) sperm and under conditions of hypoosmolality (Boryshpolets et al., 2009). However, it would be necessary to define and use a common standard unit (i.e. $\mu$ mol. $\mathrm{mg}^{-1}$ protein or nmol. $10^{9}$ spermatozoa, the second being the most common), in order to facilitate the comparison of results between various studies.

The advantage of HLPC assessment of ATP resides in the co-assessment of ADP and AMP contents which define together the Adenylate Energy Charge or AEC. AEC corresponds to the ratio of energy rich nucleotides divided by the adenylic pool and can be considered as the intracellular content of available energy expressed in percentage according to Atkinson (1968): $\mathrm{AEC}=[(\mathrm{ATP}+(\mathrm{ADP} / 2)) /(\mathrm{AMP}+\mathrm{ADP}+\mathrm{ATP})] \times 1 / 2 \times 100$. At AEC values ranging from $95 \%$ to $80 \%$, cells present optimal conditions with a high level 
of available energy. When AEC values are between $50 \%$ to $70 \%$, which corresponds to intermediate conditions, cell functions may be lowered but energy level can still be increased, then when AEC is under $50 \%$, cell suffer deeply limitating conditions with very low level of available energy.

The use of ${ }^{31} \mathrm{P}-\mathrm{NMR}$ allows assessing energetic compounds other than those of adenylic pool which participate to energetics for motility like creatine-phosphate which, added to ADP, is used as energy source in trout membrane deprived spermatozoa (Saudrais et al.,1998). (see also Dreanno et al., 1999a).

Notwithstanding, both ATP and AEC influence sperm quality. ATP content of gilthead seabream (Sparus aurata) sperm was significantly decreased after cryopreservation (Cabrita et al., 2005a). A decrease was also reported in turbot but it appears to be less deleterious because spermatozoa of this species are able to synthesize a part of their energy during sperm motion (Dreanno et al., 1997). Compared to values observed at the beginning of the spawning period, a lower ATP content and a lower Adenylate Energy Charge were recorded in seabass (Dicentrarchus labrax) semen at the end of the reproductive period as a consequence of a sperm ageing phenomenon (Dreanno et al., 1999b). A study of hake sperm have shown that after $48 \mathrm{~h}$ storage at $4^{\circ} \mathrm{C}$, the mean AEC level was 0.71 with a large individual variability of AEC and motility as well (Groison et al., 2008).

Some exceptions are reported in the cyprinid Alburnus alburnus in which no relationship was reported between ATP and sperm motility (Lahnsteiner et al., 1996). However, as a general rule sperm quality and ATP or AEC values are highly correlated, therefore, these energy describing parameters can be used as sperm quality markers. 


\section{Conclusion}

We chose to limit the extent of the present overview to the tools used to assess rapidly (and if possible in an objective manner under field conditions) the quality of sperm before fertilization. In such a way, we did not review the multiple biochemical analyses concerning sperm and try to focus on the cell state which integrates all the biochemical and molecular events which drive to sperm efficiency. Concentration and motility of sperm have been for long used to characterize sperm but these parameters were generally evaluated rapidly and subjectively. Spectrometry or image analysis and CASA help assessing them objectively and quickly with cheap devices everybody can use. However, sperm fertility integrates also the energy state of the cells and their physiological integrity which may vary with parental conditions and sperm environment condition as well.

The systematic, quantitative and accurate evaluation of different parameters influencing the fertility would allow improving our capability to make rapid progress in the control of reproduction of fish in captivity and in the development of efficient media for sperm preservation and fertilization in both aquaculture and species conservation programmes. This could be an excellent opportunity to develop collaborations and exchanges of knowhow between teams. However, it is necessary to keep in mind that machines and software packages will not understand the processes and that human observation will not be completely replaced even by sophisticated tools such as CASA. Amann and Katz (2004) mentioned that in the realm of gaining quantitative biology, it is necessary to wonder how quantitative it could be. 


\section{References}

Agnèse, J.F.; Otémé,Z. J.; Gilles, S., 1995: Effects of domestication on genetic variability, fertility, survival and growth rate in a tropical siluriform: Heterobranchus longifilis Valenciennes1840. Aquaculture, 131 , 197-204.

Alavi, S. M. H.; Linhart, O.; Coward, K.; Rodina, M., 2008: Fish Spermatology: Implications for Aquaculture Management. Fish Spermatology. pp 397-460. Alavi S. M. H.; Cosson, J.J.; Coward, K.; Rafiee, G. eds. Alpha Science international Ltd, Oxford, ISBN 978-1-84265-369-2.

Amann, R.P.; Katz, D.F., 2004: Reflections on CASA after 25 years. J. Androl., 25, 3, $317-325$

Asturiano, J.; Marco-Jiménez, F.; Pérez, L.; Balasch S.; Garzón, D.; Peñaranda, D.; Vicente, J.; Viudes-de-Castro, M.; Jover, M., 2006: Effects of HCG as spermiation inducer on European eel semen quality. Theriogenol. 66, 4, 1012-1020

Asturiano, JF.; Marco-Jimenez, F.; Penaranda, DS.; Garzon, D.L.;Perez, L.; Vicente,J.S.;Jover, M., 2007: Effect of sperm cryopreservation on the European eel sperm viability and spermatozoa morphology. Reprod. Dom. Anim. 42, 2, 162-166.

Atkinson, D.E., 1968: Energy charge of adenylate pool as a regulatory parameter. Interaction with feedback modifiers. Biochemistry, 7, 4030-4034. 
Billard, R. 1986: Spermatogenesis and spermatology od some teleost fish species. Reprod. Nut. Dev., 2, 877-920.

Billard, R.; Cosson, M.P., 1992: Some problems related to the assessment of sperm motility in freshwater fish. J. Exp. Zool. 261, 122-131.

Billard R.; Cosson, J.; Fierville, F.; Brun, R.; Rouault T.; Williot, P.,1999: Motility analysis and energetics of the Siberian sturgeon Acipenser baeri spermatozoa. J. Appl. Ichthyol. 15, 199-203.

Bjorndahl, L; Soderlund, I; Johansson,S.; Mohammadieh, M.; Pourian, M.R.; Kvist, U., 2004: Why the WHO recommendations for eosin-nigrosin staining techniques for human sperm vitality assessment must change. J. Androl., 25, 5, 671-678.

Bobe, J.; Labbé, C., 2010: Egg and sperm quality in fish. Gen. Comp. Endocrinol., 165, $3,535-548$

Boryshpolets, S Dzyuba, B Stejskal, V Linhart, O., 2009: Dynamics of ATP and movement in Eurasian perch (Perca fluviatilis L.) sperm in conditions of decreasing osmolality. Theriogenol., 72, 851-859.

Cabrita, E.; Robles, V.; Cuñado, S.; Wallace, J. C.; Sarasquete C.; Herráez M. P., 2005a: Evaluation of gilthead sea bream, Sparus aurata, sperm quality after cryopreservation in 
$5 \mathrm{ml}$ macrotubes. Cryobiol. 50, 3, 273-284.

Cabrita, E .; Robles, V .; Rebordinos, L .; Sarasquete, C .; Herráez M.P., 2005b : Evaluation of DNA damage in rainbow trout (Oncorhynchus mykiss) and gilthead sea bream (Sparus aurata) cryopreserved sperm. Cryobiol. 50, 2, 144-153.

Cabrita, E.; Robles, V.; Herraez, P., 2009: Sperm quality assessment. Methods in reproductive aquaculture. Marine and freshwater species. Cabrita, E.; Robles, V.; Herraez, P. eds. CRC Press Taylor \& Francis Group, Boca Raton, USA, ISBN 978-08493-8053-2.

Christen, R.; Gatti, J. L.; Billard, R., 1987: Trout sperm motility- the transient movement of trout sperm is related to changes in the concentration of ATP following the activation of the flagellar movement. European J. Biochem. 166, 3, 667-671.

Ciereszko, A.; Dabrowski, K., 1993: Estimation of sperm concentrationof rainbow trout, Whitefish and yellow perch using a spectophotometric technique. Aquaculture, 109, $367-373$

Cosson J. Frenetic activation of fish spermatozoa flagella entails short term motility, portending their precocious decadence J. Fish Biol. 76,240-279 (2010)

Cosson, J.; Groison, A. L.; Suquet, M.; Fauvel, C.; Dreanno, C.; Billard, R. 2008a: Marine fish spermatozoa: racing ephemeral swimmers. Reproduction 136, 3, 277-294. 
Cosson, J.; Groison, A. L.; Suquet, M.; Fauvel, C.; Dreanno, C.; Billard, R. 2008b: Studying sperm motility in marine fish: an overview on the state of the art. J. Appl. Ichthyol. $24,4,460-486$.

Dreanno, C Suquet, M Quemener, L. .; Cosson, J. .; Fierville, F. .; Normant, Y.; Billard, R., 1997: Cryopreservation of turbot (Scopthalmus maximus) spermatozoa. Theriogenol., 48, 589-603.

Dreanno, C.; Cosson, J.; Suquet, M.;Seguin, F.; Dorange, F.; Billard, R., 1999a: Nucleotide content, oxydative phosphorylation, morphology, and fertilizing capacity of turbot (Psetta maxima) spermatozoa during the motility period. Mol. Reprod. Dev. 53, $2,230-243$.

Dreanno, C.; Suquet, M.; Fauvel, C.; Le Coz, J.R.; Dorange, G.; Quemener, L. .; Billard, R.,1999b: Effect of the aging process on the quality of seabass (Dicentrarchus labrax) semen. J. Appl. Ichthyol., 15, 176-180.

Dreanno, C.; Seguin, F.; Cosson, J.; Suquet, M.; Billard,R., 2000: H-1-NMR and P-31NMR analysis of energy metabolism of quiescent and motile turbot (Psetta maxima) spermatozoa.J. Exp. Zool., 286, 5, 513-522.

Fauvel C.; Savoye, O.; Dreanno C.; Billard R.; Cosson J.; Suquet M., 1999: Characteristics of captive seabass (Dicentrarchus labrax) sperm in relation to its 
fertilisation potential. J. Fish Biol. 54, 356-369.

Flajshans, M; Cosson, J; Rodina, M.; Linhart, O., 2004: The application of image cytometry to viability assessment in dual fluorescence-stained fish spermatozoa. Cell Biol. Intl., 28, 12, 955-959.

Gage, M. J.G.; MacFarlane, C.; Yeates, S.; Shackleton, R.; Parker, G.A., 2002: Relationships between sperm morphometry and sperm motility in the Atlantic salmon. J. Fish Biol., 61, 1528-1539.

Gage, M.J.G.; MacFarlane, C.P.; Yeates, S., 2004: Spermatozoal traits and sperm competition in Atlantic salmon: Relative sperm velocity is the primary determinant of fertilization success. Current Biology,14, 44-47.

Gibbons, I.R., 1968: The biochemistry of motility. Ann. Rev. Biochem., 37, 521-546.

Groison, A-L., Suquet, M., Cosson, J., Le Coz, J-R., Jolivet, A., Garren, F. ; 2008 : Sperm biological characteristics in European hake (Merluccius merluccius) Cybium 32(2), 178.

Inaba, K., 2008: Molecular mechanisms of the activation of flagellar motility in sperm. Fish Spermatology, pp 267-280. Alavi S. M. H.; Cosson, J.J.; Coward, K.; Rafiee, G. eds. Alpha Science international Ltd, Oxford, ISBN 978-1-84265-369-2. 
Kaspar, V.; Hulak, M.; Kohlmann, K.; Vandeputte, M.; Rodina, M.; Gela, D.; Linhart, O., 2008: In vitro study on sperm competition in common carp (Cyprinus carpio L.). Cybium, 32, 2, 303-306.

Labbé, C.; Martoriati, A.; Devaux, A.; Maisse, G., 2001: Effect of Sperm Cryopreservation on Sperm DNA Stability and Progeny Development in Rainbow Trout. Mol. Reprod. Dev., 60, 397-404.

Lahnsteiner, F.; Berger, B.; Weisman, T.; Patzner, R.A., 1996: Motility of spermatozoa of Alburnus alburnus (Cyprinidae) and its relationship to seminal plasma composition and sperm metabolism. Fish Physiol. Biochem., 15, 167-179.

Linhart, O.; Rodina, M.; Gela, D.; Kocour M.; Vandeputte M., 2005: Spermatozoal competition in common carp (Cyprinus carpio): what is the primary determinant of competition success? Reproduction, 130, 705-711.

Marco-Jimenez, F.; Penaranda, D. S .; Perez, L.; Viudes-de-Castro, M. P.; Mylonas, C. C.; Jover, M.; Asturiano, J.F., 2008: Morphometric characterization of sharpsnout sea bream (Diplodus puntazzo) and gilthead sea bream (Sparus aurata) spermatozoa using computer-assisted spermatozoa analysis (ASMA). J. Appl. Ichthyol. 24, 4, 382-385.

Martinez-Pastor, F.; Cabrita, E.; Soares, F.; Anel, L.; Dinis, M. T., 2008: Multivariate cluster analysis to study motility activation of Solea senegalensis spermatozoa: a model for marine teleosts. Reproduction, 135, 4, 449-459. 
Moal, J.; Le Coz, J.R.; Samain J.F.; Daniel, J.Y., 1989: Nucleotides in bivalves: Extraction and analysis by high performance liquid chromatography (HPLC). Comp. Biochem. Physiol. (B), 93, 2, 307-316.

Mylonas C.C.; Bridges, C.; Gordin, H. ; Belmonte Rios, A.; Garcia, A.; de La Gándara, F.; Fauvel, C.; Suquet, M.; Medina, A.; Papadaki, M.; Heinisch, G.; de Metrio, G.; Corriero, A.; Vassallo-Agius, R.; Guzmán J.M.; Mañanos, E.; Zohar, Y., 2007: Preparation and administration of Gonadotropin-Releasing Hormone Agonist (GnRHa) implants for the artificial control of reproductive maturation in captive-reared Atlantic bluefin tuna (Thunnus thynnus thynnus). Rev. Fish. Sci., 15, 183-210.

Nagler, J. J.; Parsons, J. E.; Cloud, J. G., 2000: Single pair mating indicates maternal effects on embryo survival in rainbow trout, Oncorhynchus mykiss. Aquaculture, 184, $1-2,177-183$.

Nynca,J.; Ciereszko, A., 2009: Measurement of concentration and viability of brook trout (Salvelinus fontinalis)spermatozoa using computer-aided fluorescent microscopy. Aquaculture, 292, 3-4, 256-258.

Ogier De Baulny, B.; Le Vern, Y.; Kerboeuf, D.; Maisse, G., 1997: Flow cytometric evaluation of mitochondrial activity and membrane integrity in fresh and cryopreserved rainbow trout (Oncorhynchus mykiss) spermatozoa. Cryobiol. 34, 2, 141-149. 
Peñaranda, D.S.; Perez, L.; Fakriadis, G.; Mylonas, C. C.; Asturiano, J.F., 2008: Effects of extenders and cryoprotectant combinations on motility and morphometry of sea bass (Dicentrarchus labrax) spermatozoa. J. Appl. Ichthyol. 24, 4, 450-455.

Perchec, G.; Jeulin, C.; Cosson, J.; André, F.; Billard, R., 1995: Relationship between sperm ATP content and motility of carp spermatozoa. J. Cell Sci., 108, 747-753.

Perchec G.; Cosson M-P.; Cosson J.; Jeulin C.; Billard R., 1996: Morphological and kinetic changes of carp (Cyprinus carpio) spermatozoa after initiation of motility in distilled water. Cell Motility and the Cytoskeleton. 35, 113-120.

Rurangwa, E; Volckaert, F. A. M.; Huyskens, G.; Kime, D. E.; Ollevier, F., 2001: Quality control of refrigerated and cryopreserved semen using computer-assisted sperm analysis (CASA), viable staining and standardized fertilization in African catfish (Clarias gariepinus). Theriogenol. 55, 3, 751-769.

Rurangwa, E.; Kime, D. E.; Ollevier, F.; Nash, J. P., 2004: The measurement of sperm motility and factors affecting sperm quality in cultured fish. Aquaculture, 234, 1-4, 1-28.

Saillant, E.; Chatain, B .; Fostier A.; Przybyla, C .; Fauvel C., 2001 : Parental influence on early development in the European sea bass (Dicentrarchus labrax). J. Fish Biol. 58, $6,1585-1600$. 
Saudrais C.; Fierville F.; Cibert C.; Loir M.; Le Rumeur E.; Cosson, J., 1998: The use of creatine-phosphate plus ADP as energy source for motility of membrane deprived trout spermatozoa. Cell Motility and the Cytoskeleton, 41, 91-106.

Suquet, M.; Omnes, M.H.; Normant, Y.; Fauvel C., 1992: Assessment of sperm concentration and motility in turbot (Scophthalmus maximus). Aquaculture, 101, 177185.

Tuset, V. M.; Trippel, E. A.; de Montserrat, J., 2008: Sperm morphology and its influence on swimming speed in Atlantic cod. J. Appl. Ichthyol. 24, 4, 98-405.

Van Look, K. J. W.; Kime, D. E., 2003: Automated sperm morphology analysis in fishes: the effect of mercury on goldfish sperm. J. Fish Biol., 63, 1020-1033

Wilson-Leedy J.G.; Ingermann R. L., 2006: Computer assisted sperm analysis. http://rsb.info.nih.gov/ij/plugins/casa.html

Wilson-Leedy J.G.; Ingermann R. L., 2007: Development of a novel CASA system based on open source software for characterization of zebrafish sperm motility parameters. Theriogenol., 67, 3, 661-672.

Wilson-Leedy, J. G.; Kanuga, M. K.; Ingermann, R. L., 2009: Influence of osmolality 
and ions on the activation and characteristics of zebrafish sperm motility. Theriogenol., 71, 7, 1054-1062.

Zilli, L.; Schiavone, R.; Zonno, V.; Storelli C.; Vilella S., 2003: Evaluation of DNA damage in Dicentrarchus labrax sperm following cryopreservation. Cryobiol., 47, 3, 227-235.

Zilli, L.; Schiavone, R.; Zonno, V.; Storelli C.; Vilella S., 2004: Adenosine Triphosphate Concentration and b-D-Glucuronidase Activity as Indicators of Sea Bass Semen Quality, Biol.Reprod. 70, 1679-1684.

Zohar, Y., 1996: New approachesfor the manipulation of ovulation and spawning in farmed fish. Bull. Natl. Res. Inst. Aquac., Suppl. 2, 43-48. 


\section{Captions}

Table 1: Factors affecting reproductive success using sperm of various fish species: an attempt to synthesize the causes of sperm quality variations as revealed from a literature survey.

Table 2: Relationship between sperm concentration (SpConc) and optical density (DO) as determined by photometry at $260 \mathrm{~nm}$ wavelength for a number of fish species $\left(\mathrm{R}^{2}=\right.$ Coefficient of determination for the regression equations)

Fig 1: Light absorption spectrum of sperm A) interspecific variations showing the common peak or shoulder at $260 \mathrm{~nm}$ for seabass, seabream and turbot; B) intraspecific variations in tuna.

Fig 2: Relation between optical density and number of spermatozoa per milliter of diluted semen as expressed by a linear regression derived from 10 increasing dilutions of semen of each of 3 cod (Gadus morhua) males.

Fig 3: Simultaneous display of tuna sperm motility assessment at different times post activation, by i) 2 observers evaluating the percentage of motile cells (line); ii) individual curvilinear velocity values recorded by CASA (Hobson Sperm Tracker)

Fig 4: Display of tracks of tuna spermatozoa subject ot different activating media recorded using free software CASA from image $\mathbf{J}$ and mean values of motility parameters: A) sperm at 10 seconds after activation by seawater(SW). B) Sperm of the same sample at $10 \mathrm{~s}$ after activation by a solution of glucose at 1000 mOsm. The major difference between these 2 cases is the straightness (VSL/VAP) while the velocities are not significantly different. (VCL: Curvilinear velocity; VAP: Average path velocity; VS: Straightline velocity; WOB: Wobble; BCF: Beat Cross Frequency 


\section{Table 1}

\begin{tabular}{|c|c|c|c|c|c|c|c|c|c|}
\hline \multirow[b]{2}{*}{ origin } & \multirow[b]{2}{*}{ determining factor } & \multirow{2}{*}{$\begin{array}{l}\text { gonad } \\
\text { gsi }\end{array}$} & \multicolumn{7}{|c|}{ sperm } \\
\hline & & & volume & concentration & motility & $\begin{array}{l}\text { membrane } \\
\text { integrity }\end{array}$ & energy & $\begin{array}{l}\text { DNA } \\
\text { integrity }\end{array}$ & Fertility \\
\hline \multirow[t]{7}{*}{ Parental effect } & temperature & $x$ & $x$ & & & & & & \\
\hline & photoperiod & $\mathbf{x}$ & $\mathbf{x}$ & & & & & & \\
\hline & xenobiotics & $x$ & $x$ & & & & & & $\mathbf{x}$ \\
\hline & domestication & $\mathbf{x}$ & $\mathbf{x}$ & & & & & & \\
\hline & nutrition & $\mathbf{x}$ & & & & $\mathbf{x}$ & & & \\
\hline & selection & & $\mathbf{x}$ & & & & & & $\mathbf{x}$ \\
\hline & unknown & & & & & & & & $\mathbf{x}$ \\
\hline \multirow[t]{2}{*}{ Sperm physiology } & testicular sperm & & & & $x$ & & & & $\mathbf{x}$ \\
\hline & ageing & & $\mathbf{x}$ & $\mathbf{x}$ & $\mathbf{x}$ & & $\mathbf{x}$ & & $\mathbf{x}$ \\
\hline \multirow[t]{5}{*}{$\begin{array}{l}\text { Fertilization } \\
\text { medium }\end{array}$} & osmolarity & & & & $x$ & & & & \\
\hline & ions & & & & $x$ & & & & \\
\hline & $\mathrm{pH}$ & & & & $\mathbf{x}$ & & & & $\mathbf{x}$ \\
\hline & xenobiotics & & & & $x$ & & & & $\mathbf{x}$ \\
\hline & ions & & & & $\mathbf{x}$ & & & & \\
\hline \multirow[t]{4}{*}{ Human interaction } & $\begin{array}{l}\text { hormonal } \\
\text { stimulation }\end{array}$ & & $\mathbf{x}$ & $\mathbf{x}$ & $\mathbf{x}$ & & & & \\
\hline & preservation & & & & & & & & \\
\hline & fresh chilled & & & & $\mathbf{x}$ & & $\mathbf{x}$ & & $\mathbf{x}$ \\
\hline & cryopreservation & & & & $\mathbf{x}$ & $\mathbf{x}$ & $\mathbf{x}$ & $\mathbf{x}$ & $\mathbf{x}$ \\
\hline
\end{tabular}


table 2

\begin{tabular}{|c|c|c|}
\hline & $\begin{array}{l}\text { Sperm concentration } \\
\qquad\left(* 10^{10} \mathrm{spz} \mathrm{ml}^{-1}\right)\end{array}$ & $\mathrm{R}^{2}$ \\
\hline $\begin{array}{c}\text { Seabass } \\
\text { (Dicentrarchus labrax) }\end{array}$ & SpConc $=4.73 *$ DO -0.12 & 0.97 \\
\hline $\begin{array}{c}\text { Seabream } \\
\text { (Sparus auratus) }\end{array}$ & SpConc $=8.54 *$ DO-2.05 & 0.96 \\
\hline $\begin{array}{c}\text { Turbot } \\
(\text { Psetta maxima })\end{array}$ & $\mathrm{SpConc}=8 *$ DO -2.8 & 0.95 \\
\hline $\begin{array}{c}\text { Wreckfish } \\
\text { (Polyprion americanus) }\end{array}$ & SpConc $=4.25 *$ DO-0.09 & 0.98 \\
\hline $\begin{array}{c}\text { Tuna } \\
\text { (Thunnus thunnus thynnus) }\end{array}$ & SpConc $=6.16 *$ DO -1.09 & 0.84 \\
\hline $\begin{array}{c}\text { Catfish } \\
\text { (Pangassius Hypophthalmus) }\end{array}$ & SpConc $=4.97 *$ DO -0.97 & 0.86 \\
\hline $\begin{array}{c}\text { Cod } \\
\text { (Gadus morhua) }\end{array}$ & SpConc $=3.52 *$ DO -0.53 & 0.99 \\
\hline
\end{tabular}


Figure 1

A

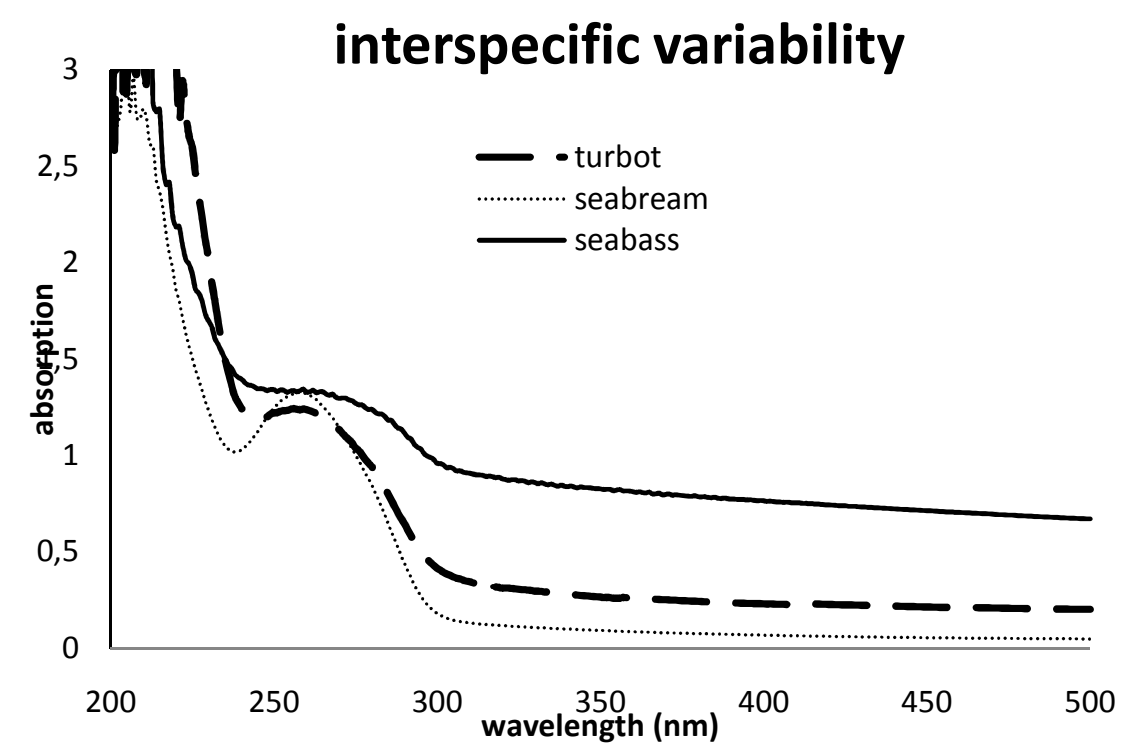

B

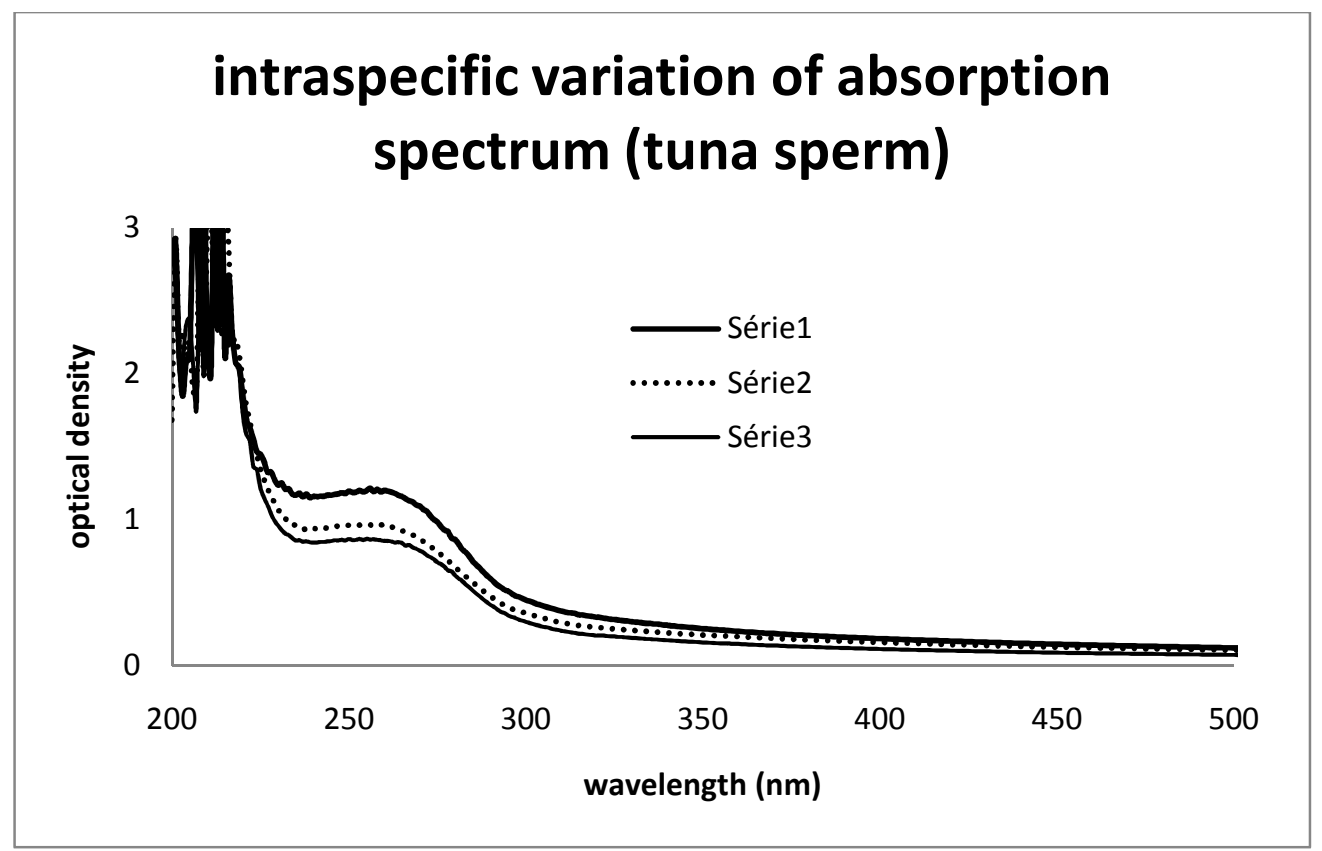


figure 2

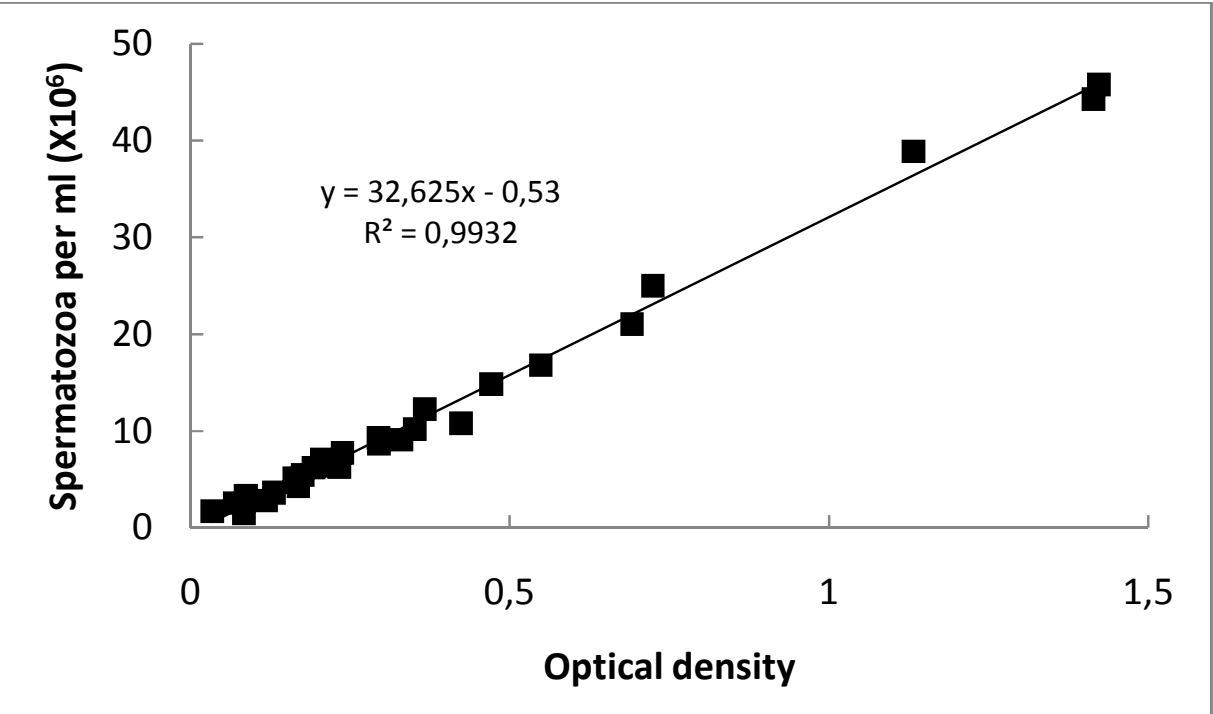


figure 3

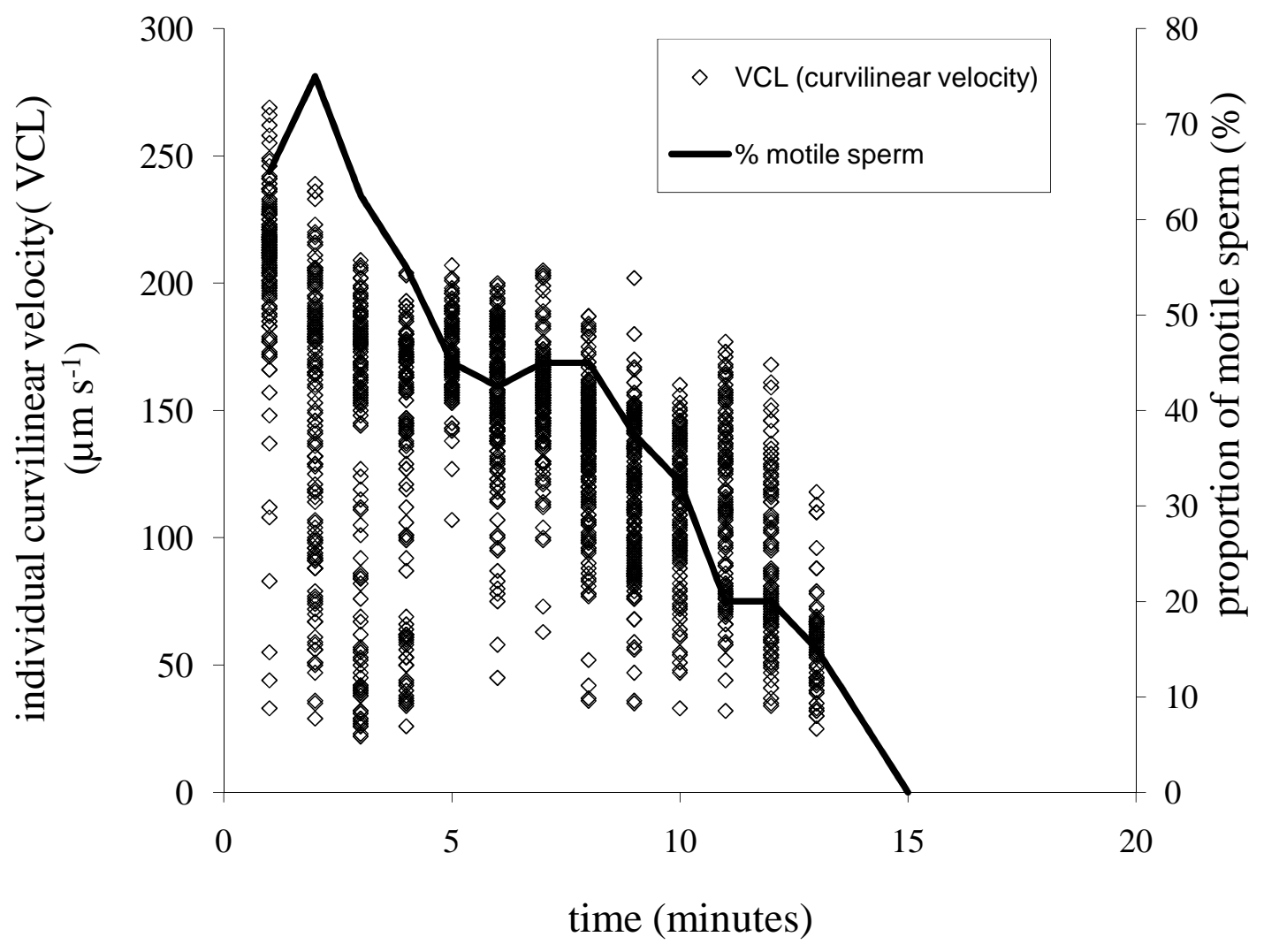


figure 4

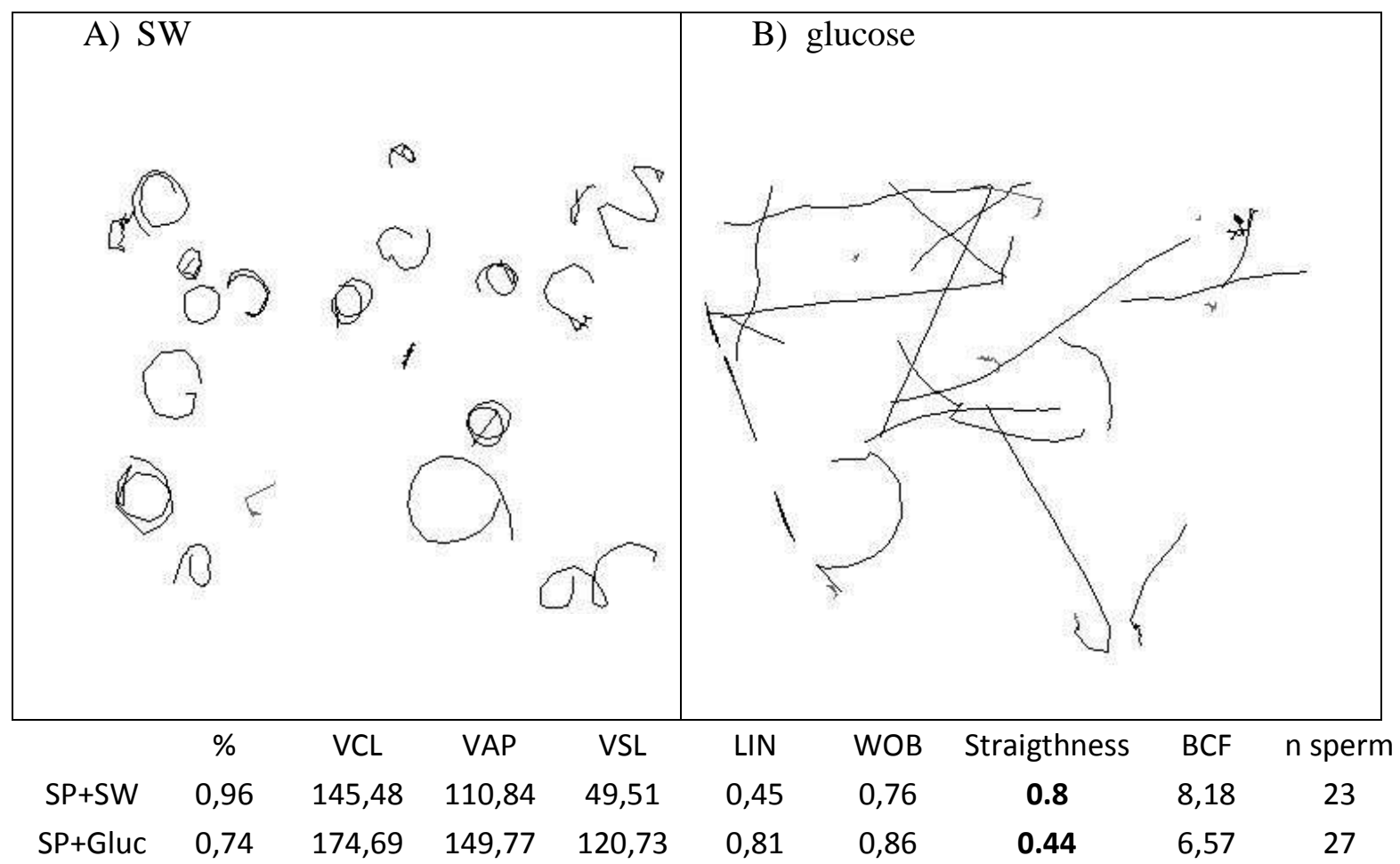

